\title{
FILM OF CHITOSAN-CARBOXYMETHYL CELLULOSEPOLYELECTROLYTE COMPLEX AS METHYLENE BLUE ADSORBENT
}

\author{
Febi Indah Fajarwati ${ }^{{ }^{*}}$, Eko Sugiharto ${ }^{2}$, Dwi Siswanta ${ }^{3}$ \\ ${ }^{1}$ Program Studi Ilmu Kimia FMIPA, Universitas Islam Indonesia, Yogyakarta \\ ${ }^{2,3}$ Program Studi Kimia FMIPA, Universitas Gadjah Mada, Yogyakarta \\ *email: febiindah30@gmail.com
}

\begin{abstract}
ABSTRAK
Telah dilakukan pembuatan film kompleks polielektrolit kitosan-karboksimetil selulosa (CMC) untuk pengujian pengaruh rasio volume CMC:kitosan $(1: 1 ; 3: 2 ; 7: 3)$. Karakterisasi film dilakukan dengan uji kuat tarik, medium asam basa, dan penyerapan air serta dilakukan uji adsorpsi terhadap biru metilen. Hasil Karakterisasi menunjukkan sifat mekanik film menurun dengan bertambahnya jumlah karboksimetil selulosa dan film stabil pada $\mathrm{pH}>4$. Kondisi optimum adsorpsi diperoleh pada film F3 (ratio volume CMC:kitosan 7:3) dengan kapasitas adsorpsi sebesar $8,38 \times 10^{-5} \mathrm{~mol} / \mathrm{g}$ selama 30 menit.
\end{abstract}

Kata kunci: Kitosan, karboksimetil selulosa, kompleks polielektrolit, adsorpsi.

\begin{abstract}
The chitosan-carboxymethyl cellulose polyelectrolyte complex film have been synthesized. This films was used study the effect of volume ratio CMC:chitosan $(1: 1 ; 3: 2 ; 7: 3)$. The film were characterized with Tengsile Strength Tester, stability of film in the acid-base medium and the ability to adsorp water were tested. The adsorption activities of film towards methylene blue also was studied including the effect of film composition. The result showed that the mechanical properties of film decreased as carboxymetyl cellulosa increased and has stability at $\mathrm{pH}>4$. The optimum condition of methylene blue adsorption of film F3 (volume ratio CMC:chitosan 7:3) with adsorption capacity at $8,38 \times 10^{-5} \mathrm{~mol} / \mathrm{g}$ at 30 minute.
\end{abstract}

Key Word: Chitosan, Carboxymethylcellulosa, polyelectrolyte complex, adsorption.

\section{PENDAHULUAN}

Zat warna merupakan salah satu limbah yang keberadaannya mengkhawatikan. Sekitar $15 \%$ dari total produksi zat warna di dunia digunakan oleh industri tekstil dan limbahnya dibuang di lingkungan (Houas dkk., 2001). Salah satu zat warna yang banyak digunakan adalah biru metilen karena sifatnya yang mudah larut dalam air dan harganya ekonomis. Methylene blue (MB) merupakan senyawa kimia aromatik heterosiklik dengan rumus molekul : $\mathrm{C}_{16} \mathrm{H}_{18} \mathrm{~N}_{3 \mathrm{~S}} \mathrm{Cl}(\mathrm{MW}=319,65$ g/mol) (Gambar 1) (Ansari dkk., 2011).<smiles>CN(C)c1ccc2nc3ccc(=[N+](C)C)cc-3sc2c1</smiles>

Gambar 1. Struktur biru metilena 
Beberapa metode telah dilakukan dalam proses pengolahan limbah zat warna, salah satu metode yang saat ini masih banyak digunakan adalah metode adsorpsi. Hal ini, karena metode adsorpsi dianggap sebagai metode yang efektif dan ekonomis untuk menghilangkan zat pewarna di air limbah serta memiliki penerapan yang luas dalam pengolahan air limbah (Wawrzkiewicz dkk., 2010; Chiou dkk., 2003).

Sejauh inipengembangan bahan adsorben terus dilakukan, salah satunya biosorben. Kitosan merupakan salah satu biosorben yang banyak dimanfaatkan sebagai adsorben zat warna.Tanasale (2012) menggunakan kitosan dari limbah kulit kepiting rajungan untuk mengadsorpsi biru metilen dengan kapasitas adsorpsi yang diperoleh sebesar
Kitosan merupakan polisakarida kationik yang dapat digunakan sebagai adsorben untuk menghilangkan logam berat maupun zat warna karena adanya gugus amino dan hidroksil, yang dapat berfungsi sebagai situs aktifnya (Wu dkk., 2001). Namun kitosan kurang efektif jika langsung digunakan sebagai adsorben karena adanya gugus hidroksil pada struktur kitosan (Gambar 2) yang menyebabkan sifat hidrofilisitasnya rendah. Oleh karena itu diperlukan suatu modifikasi untuk meningkatkan efektifitas kitosan dalam proses adsorpsi. Karboksimetil selulosa $\quad$ (CMC) merupakan salah satu polisakarida anionik yang dapat dipadukan dengan kitosan membentuk kompleks polielektrolit atau yang di singkat PEC. $4 \mathrm{mg} / \mathrm{g}$.

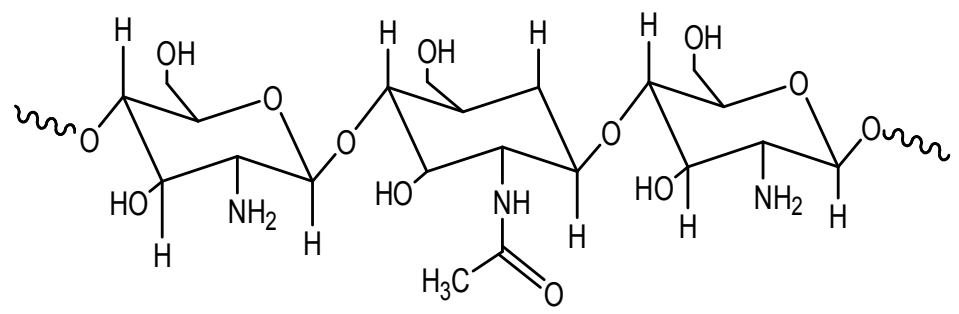

Gambar 2. Struktur kitosan

Pembuatan PEC ini bergantung pada penggunaannya, salah satu bentuk PEC yang memiliki kelebihan pada metode adsorpsi adalah dalam bentuk film karena akan memudahkan proses pemisahan antara adsorbat dan adsorbennya. Selain itu, karboksimetil selulosa (CMC) diketahui memiliki viskositas tinggi, non toksik dan larut dalam air (Tongdeesontorn dkk., 2011). 
Pembentukkan PEC dari kitosan-

CMC diharapkan dapat menghasilkan film yang memiliki sifat hidrofilisitas yang tinggi sehingga akan meningkatkan efektifitas adsorpsi film. Dalam penelitian ini penambahan CMC pada PEC kitosan-CMC akan mempengaruhi sifat hidrofilisitas (swelling) film yang akan berpengaruh pada proses adsorpsinya. Oleh karena itu, penelitian yang kami lakukan bertujuan untuk mengetahui pengaruh penambahan CMC terhadap sifat mekanik dan kapasitas adsorpsi film terhadap zat warna biru metilen.

\section{METODE PENELITIAN}

\section{Alat:}

Alat-alat yang digunakan dalam penelitian ini meliputi seperangkat alat gelas, petridish, neraca analitik (Mattler Toledo AB54-S), pengaduk magnet, Spektrofotometer Inframerah (Prestige21, Shimadzu), Scanning Electron Microscopy (JSM 6510LA), Spektrofotometer UV-Vis (GBC Scientific Equipment, Cintra 2020), pH universal (Merck), alat penggojog (Marius), $\mathrm{pH}$ meter (TOA model HM5B), oven listrik (Media), Tensile Strength Tester (Zwick/Z05) dan kertas saring.
Bahan:

Bahan yang digunakan pada penelitian ini adalah biru metilen (Merck), asam asetat $\left(\mathrm{CH}_{3} \mathrm{COOH}\right)$ glasial 96\%, $\mathrm{NaOH}, \mathrm{HCl} 37 \%$, kitosan dengan nilai deasetilasi (DD) 87\%, (CV. Ocean Fresh, IPB), karboksimetil selulosa (CMC) (CV. Chemix Pratama), akuades dan akuabides.

\section{Metode:}

\section{Pembuatan film Kitosan-CMC}

Metode pembuatan film PEC mengacu pada metode Sugita dkk (2010) yang kemudian dilakukan modifikasi untuk membuat film PEC kitosan-CMC. Pembuatan film PEC kitosan-CMC dilakukan dengan mencampurkan larutan CMC $0,1 \%(w / v)$ pada volume tertentu ditambahkan ke sejumlah volume kitosan $1 \%(\mathrm{w} / \mathrm{v})$ dengan volume total $50 \mathrm{~mL}$ (rasio volume CMC:kitosan $=1: 1 ; 3: 2$; 7:3), campuran CMC-kitosan kemudian diaduk selama 20 jam. Sebanyak $5 \mathrm{~mL}$ campuran PEC yang telah terbentuk dicetak menggunakan petridish untuk diuapkan pada suhu $80-85^{\circ} \mathrm{C}$.

Film yang telah kering kemudian direndam dengan $\mathrm{NaOH} 0,2 \mathrm{M}$ selama \pm 12 jam yang dilanjutkan dengan pencucian menggunakan akuades sampai netral. Film yang terbentuk dikeringkan 
pada suhu ruangan dan disimpan untuk analisis selanjutnya.

\section{Karakterisasi Film PEC}

\section{a. Uji penyerapan air}

Film PEC yang telah terbentuk ditimbang sebagai berat kering ( $W_{\text {kering }}$ ) kemudian film direndam dalam $30 \mathrm{~mL}$ akuabides, selanjutnya permukaan film dikeringkan dengan kertas saring dan ditimbang kembali $\left(W_{\text {basah }}\right)$. Penentuan kemampuan penyerap air diperoleh dari rumus: Penyerapan air $(\%)=$

$$
\frac{W_{\text {basah_- }} W_{\text {kering }}}{W_{\text {kering }}} \times 100 \%
$$

\section{b. Uji kestabilan dalam medium asam basa}

Film PEC yang telah terbentuk disiapkan dan ditimbang. Film PEC selanjutnya direndam selama 7 hari dalam $10 \mathrm{~mL}$ akuades yang diatur $\mathrm{pH}$-nya melalui penambahan larutan $\mathrm{HCl} 1 \mathrm{M}$ dan $\mathrm{NaOH} \quad 0,2$ M. Setelah proses perendaman, diamati perubahan fisik film yang terjadi.

\section{c. Uji kuat tarik}

Film PEC yang telah terbentuk diuji kuat tariknya menggunakan menggunakan alat Tensile Strength Tester, pengujian dilakukan pada Test speed $10 \mathrm{~mm} / \mathrm{min}$.

\section{d. Uji adsorpsi biru metilena}

Film yang terbentuk dikontakkan ke dalam $30 \mathrm{~mL}$ larutan biru metilen 25
mg/L kemudian digojog selama 30 menit. Film dipisahkan dari larutan dan konsentrasi biru metilen yang tersisa pada larutan diukur menggunakan spektrofotometer UV-Vis pada panjang gelombang maksimum.

\section{PEMBAHASAN}

\section{a. Uji penyerapan air}

Pengujian daya serap air dilakukan dengan merendam film PEC dalam akuabides dalam berbagai variasi waktu. Gambar 3.menunjukkan penyerapan air oleh film PEC kitosanCMC dengan variasi waktu dipengaruhi oleh kandungan $\mathrm{CMC}$ dalam film dimana CMC mempunyai sifat hidrofilik yang baik oleh adanya gugus -COOHdan $\mathrm{OH}$, dimana gugus karboksil $\mathrm{CMC}$ akan membentuk ikatan hidrogen dengan air, sehingga semakin banyak CMC maka penyerapan air oleh film PEC kitosanCMC akan semakin besar.

Hasil penyerapan air dengan fungsi waktu 60, 120 dan 240 menit menunjukkan kecenderungan hasil yang sama dengan semakin lama waktu perendaman maka penyerapan air oleh film PEC akan semakin besar dan penyerapan air optimum untuk setiap waktu diperoleh pada komposisi film PEC F3. Sedangkan pada film PEC F1 dan F2 nilai persentase penyerapan air 
rendah, hal ini disebabkan jumlah CMC yang ditambahkan relatif lebih kecil sehingga gugus $-\mathrm{COO}^{-}$yang terdapat pada film kurang melimpah sehingga interaksi dengan gugus $\mathrm{H}^{+}$pada air juga berkurang. Hal inilah yang menjadi persentase penyerapan air oleh film PEC F1 dan F2 rendah.

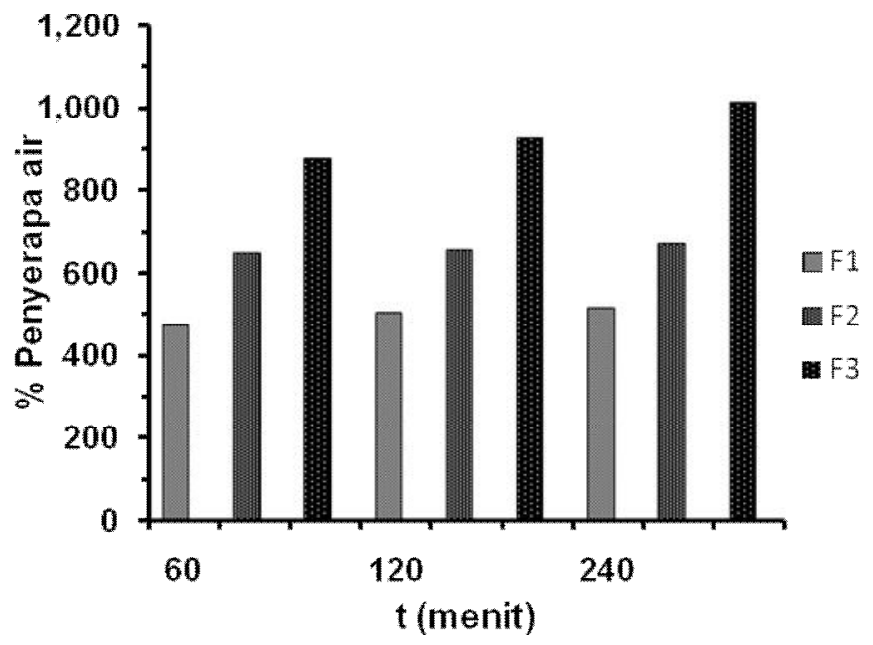

Gambar 3. Diagram hasil uji penyerapan air film PEC kitosan-CMC.

\section{b. Uji kestabilan dalam medium asam basa}

Pengujian ini dilakukan untuk mengetahui kestabilan film PEC dalam media asam dan basa yang dilakukkan dengan penambahan larutan $\mathrm{HCl}$ dan
$\mathrm{NaOH}$. Hasil pengujian (Tabel 1.) menunjukkan bahwa film PEC dengan berbagai variasi komposisi mengalami kerusakan pada $\mathrm{pH} 1$ dan 2 dalam waktu perendaman 1 hari dan pada $\mathrm{pH} 3$ film mengalami berubahan fisik (gel) setelah perendaman 7 hari.

Tabel 1. Uji kestabilan medium asam basa film PEC kitosan-CMC

\begin{tabular}{lcccccc}
\hline pH & \multicolumn{5}{c}{ Film PEC Kitosan-CMC } \\
& \multicolumn{2}{c}{ F1 } & \multicolumn{2}{c}{ F2 } & \multicolumn{2}{c}{ F3 } \\
\cline { 2 - 7 } & Hari & Ket & Hari & Ket & Hari & Ket \\
\hline $\mathbf{1}$ & 0 & larut & 0 & larut & 0 & larut \\
$\mathbf{2}$ & 0 & larut & 0 & larut & 0 & larut \\
$\mathbf{3}$ & 7 & Gel & 7 & Gel & 7 & Gel \\
$\mathbf{4}$ & 7 & Stabil & 7 & Stabil & 7 & Stabil \\
$\mathbf{9}$ & 7 & Stabil & 7 & Stabil & 7 & Stabil \\
$\mathbf{1 0}$ & 7 & Stabil & 7 & Stabil & 7 & Stabil \\
\hline
\end{tabular}




\begin{tabular}{lllllll}
\hline $\mathbf{1 1}$ & 7 & Stabil & 7 & Stabil & 7 & Stabil \\
$\mathbf{1 2}$ & 7 & Stabil & 7 & Stabil & 7 & Stabil \\
\hline
\end{tabular}

Kerusakan film PEC pada $\mathrm{pH}<3$ dikarenakan adanya gugus $\mathrm{H}^{+}$bebas yang akan mengurangi interaksi gugus $\mathrm{NH}_{3}{ }^{+}$dengan gugus $-\mathrm{COO}^{-}$pada $\mathrm{CMC}$ dan gugus $-\mathrm{COO}^{-}$pada film $\mathrm{PEC}$ cenderung akan membentuk $-\mathrm{COOH}$ yang mampu meningkatkan kelarutannya dalam air sehingga film akan larut dan tidak stabil. Sedangkan pada $\mathrm{pH}>3$ film PEC mulai stabil sampai dengan pH 12 (basa) adanya pengurangan gugus $\mathrm{H}^{+}$dan ikatan gugus $\mathrm{NH}_{3}{ }^{+}$dengan gugus $-\mathrm{COO}^{-}$ cenderung stabil sehingga film tidak rusak pada $\mathrm{pH}$ tersebut.

\section{c. Uji kuat tarik}

Adapun tujuan dari pengujian ini yaitu untuk mengetahui pengaruh rasio volume kitosan dan $\mathrm{CMC}$ terhadap sifat mekanik film PEC kitosan-CMC.

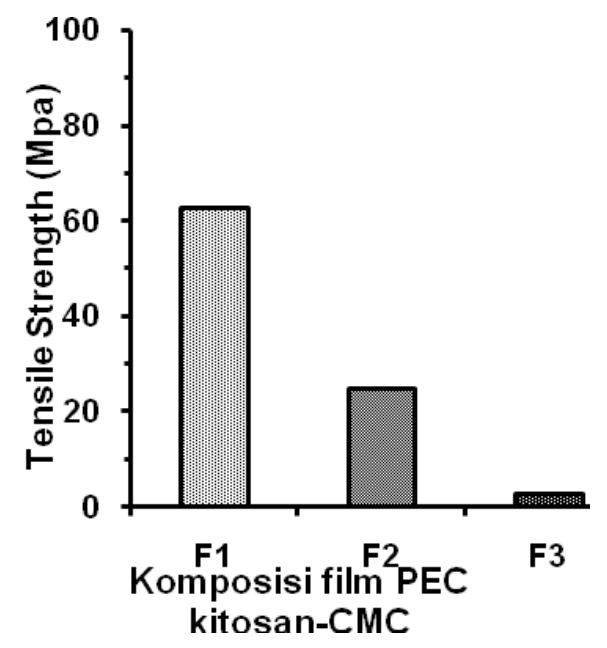

Gambar 4. Diagram hasil kuat tarik film PEC kitosan-CMC

Hasil pengujian yang ditunjukkan

pada Gambar 4. diperoleh bahwa penambahan CMC mempengaruhi kuat tarik film, semakin banyak jumlah $\mathrm{CMC}$ kuat tarik film PEC semakin rendah. Rendahnya kuat tarik film dipengaruhi oleh interaksi antara kitosan dengan CMC, dimana situs aktif kitosan $\left(-\mathrm{NH}_{3}{ }^{+}\right)$ tidak dapat berikatan secara penuh dengan situs aktif $\mathrm{CMC}\left(-\mathrm{COO}^{-}\right)$yang jumlahnya lebih banyak sehingga kuat tarik film menurun. Kuat tarik optimum film PEC kitosan-CMC diperoleh pada komposisi film PEC F1 dengan nilai Tensile Strength sebesar $63 \mathrm{MPa}$ dimana pada komposisi tersebut jumlah antara kitosan dan CMC sebanding sehingga menghasilkan ikatan antara gugus $\mathrm{NH}_{3}{ }^{+}$ dengan $-\mathrm{COO}^{-}$terpenuhi dan kuat. 
d. Uji adsorpsi film PEC kitosan-CMC terhadap biru metilen

Variasi rasio volume

CMC:kitosan dalam pembuatan film PEC kitosan-CMC mempengaruhi efektifitas film PEC dalam mengadsorpsi biru metilen. Kedua bahan tersebut masing- masing memiliki gugus fungsional yang digunakan untuk berinteraksi satu dengan lainnya juga dimungkinkan untuk berinteraksi dengan biru metilen. Hasil adsorpsi film dengan rasio volume CMC:kitosan dapat dilihat pada Gambar 5.

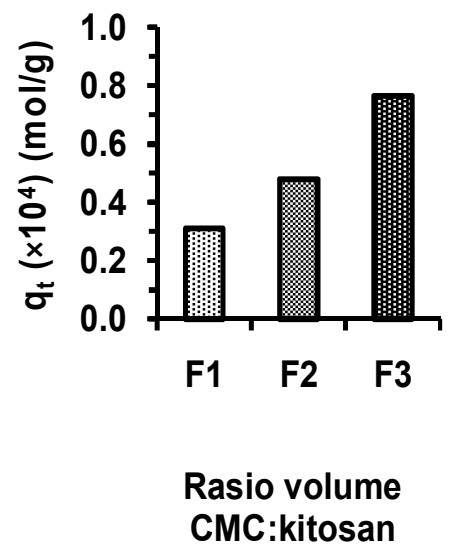

Gambar 5. Diagram pengaruh rasio volume CMC:kitosan terhadap adsorpsi biru metilen

Dilihat dari kapasitas adsorpsi biru metilen pada variasi rasio volume CMC:kitosan (Gambar 5), penambahan CMC secara umum meningkatkan nilai kapasitas adsorpsi biru metilen oleh film PEC, mulai dari $3,41 \times 10^{-5} \mathrm{~mol} / \mathrm{g}$ pada film F1 meningkat menjadi $5,15 \times 10^{-5}$ mol/g pada film PEC F2 dan kapasitas adsorpsi paling optimum diperoleh pada komposisi film PEC F3 dengan nilai $\mathrm{q}_{\mathrm{t}}$ sebesar $8,38 \times 10^{-5} \mathrm{~mol} / \mathrm{g}$. Hal ini disebabkan oleh kandungan gugus - $\mathrm{COO}^{-}$ yang melimpah seiring bertambahnya jumlah CMC dalam film dimana gugus ini merupakan situs aktif yang memiliki kecenderungan untuk berinteraksi dengan muatan positif $\left(=\mathrm{N}^{+}\left(\mathrm{CH}_{3}\right)_{2}\right)$ pada biru metilen, interaksi yang terbentuk merupakan interaksi elektrostatik dan reversible (Soedjak, 1994).

Penurunan kapasitas adsorpsi biru metilen oleh film PEC F2 dan F1 disebabkan oleh meningkatnya rasio kitosan dalam film PEC kitosan-CMC yang relatif banyak dibandingkan pada film PEC F3 sehingga situs aktif -COOdalam film relatif lebih sedikit dan adsorpsi biru metilen menjadi rendah. 
Kitosan merupakan polikationik yang bermuatan positif dari gugus $-\mathrm{NH}_{2}$ yang terprotonasi menjadi $-\mathrm{NH}_{3}{ }^{+}$ sehingga kecenderungan untuk berinteraksi dengan biru metilen sedikit dan cenderung untuk tolak menolak (Oktari, 2014). Meskipun demikian, pada film PEC F1 biru metilen masih dapat teradsorpsi. Hal ini terjadi dimungkinkan karena masih ada muatan negatif $\left(-\mathrm{COO}^{-}\right)$ dari CMC yang tidak berinteraksi dengan muatan positif dari kitosan sehingga biru metilen masih dapat terikat (teradsorp) oleh film.

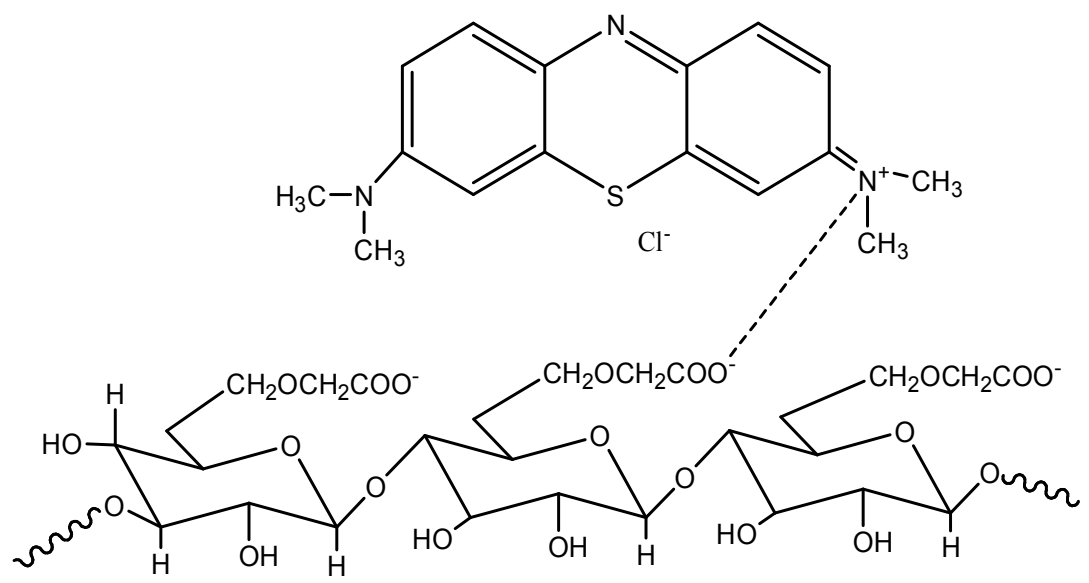

Gambar 6. Perkiraan interaksi yang terjadi antara biru metilen dengan situs aktif film PEC (Al-Ghouti dkk., 2010)

Interaksi dengan biru metilen juga dimungkinkan oleh sifat hidofilik antara film dengan biru metilen dimana semakin banyak jumlah CMC sifat hidrofilik film PEC semakin meningkat sehingga biru metilen dapat teradsorpsi.

\section{KESIMPULAN}

Hasil penelitian memberikan kesimpulan:

1. Sifat mekanik film turun seiring bertambahnya jumlah CMC dan kestabilan film turun pada $\mathrm{pH}<3$.

2. Komposisi CMC dalam pembuatan film PEC berpengaruh terhadap penyerapan air dan kemampuan adsorpsi film terhadap biru metilen. Kapasitas adsorpsi film semakin meningkat seiring bertambahnya jumlah CMC, kapasitas adsorpsi optimum diperoleh pada film F3 sebesar $8,38 \times 10^{-5} \mathrm{~mol} / \mathrm{g}$.

\section{SARAN}

Disarankan untuk penelitian selanjutnya diperlu tambahan zat kimia lain untuk meningkatkan kestabilan dan sifat mekanik film PEC kitosan-CMC.

\section{DAFTAR PUSTAKA}

Al-Ghouti, M. A., Li, J., Salamh, Y., AlLaqtah, N., Walker, G. dan Ahmad, M. N. M., 2010, 
Adsorption Mechanisms of Removing Heavy Metals and Dyes from Aqueous Solution Using Date Pits Solid Adsorbent, J. Hazard Mater, 176, 510-520.

Ansari, R., Mosayebzadeh, Z., Keivani, M.B., dan Mohammad-khah, A., 2011, Adsorption of Cationic Dyes from Aqueous Solution using Polyaniline Conducting Polymer as a Novel Adsorbent, J.Adv.Sci.Res, 2, 27-34.

Chiou, M. S. dan Li, H. Y., 2003a, Adsorption Behavior of Reactive Dye in Aqueous Solution On Chemical Cross-Linked Chitosan Beads, Chemosphere, 50, 10951105.

Chiou, M. S., Ho, P. Y., dan Li, H. Y., 2003b, Adsorption Behavior of Dye AAVN and RB4 in Acid Solution on Chemically CrossLinked Chitosan Beads, J. Chin Inst Chem Engrs, 34, 625-634.

Houas, A., Lacheb, H., Ksibi, M., Elaloui, E., Guillard, C., dan Herman, J.M., 2001, Photocatalytic Degradation Patway of Methylene Blue in Water, Appl. Catal. B:Environ., 31, 145-157.

Oktari, L.R., 2014, Pembuatan Film Komposit Kompleks Polielektrolit Kitosan-k-Karaginan dan
Pemanfaatannya Sebagai Adsorben Metilen Biru, Tesis, Jurusan Ilmu Kimia, Universitas Gadjah Mada, Yogyakarta.

Sugita, P., Achmadi, S.S., dan Yundhana, Y., 2010, Perilaku Disolusi Ketoprofen Tersalut Gel KitosanKarboksimetilselulosa (CMC), $J$. Natur Indonesia, 13(1), 21-26.

Tanasale, B.F.J.D.P, Kilaiy, A., Marsela, A.L., 2012, Kitosan dari Limbah Kulit Kepiting Rajungan (Portunus sanginolentus L.) Sebagai Adsorben Zat Warna Biru Metilena, J. Natur, Indo, 14, 165171.

Toongdeesoontorn, W., Mauer, L. J., Wongruong, S., Sriburi, P., Rachtanapun an P., 2011, Effect of Carboxymethyl Cellulose Concentration on Physical Properties of Biodegradation Cassava Starch-Based Films, Chem. Cent. J., 5 (6).

Soedjak, H. S., 1994, Colorimetri Determination of Carragenans and Other Anionic Hydrocolloids with Methylene Blue, Anal. Chem., 66, 4514-4518.

Grasianto, 2014, Enkapsulasi Kurkumin dalam Nanopartikel KitosanPektin Tertaut Silang Glutaraldehida dan Studi Pelepasannya Secara In Vitro, 
Tesis, Jurusan Ilmu Kimia,

Universitas Gadjah Mada,

Yogyakarta.

Wawrzkiewicz, M., dan Hubicki, Z., 2010, Equilibrium and Kinetic Studies on the Sorption of Acidic Dye by Macroporous Anion

Exchanger, Chemical

Engineering. J., 157, 29-34.

Wu, F. C., Tseng, R. L., dan Juang, R.S, 2001, Kinetic Modeling of Liquid-Phase Adsorption of Reactive Dyes and Metal Ions on Chitosan, Wat. Res., 35, 613-618. 